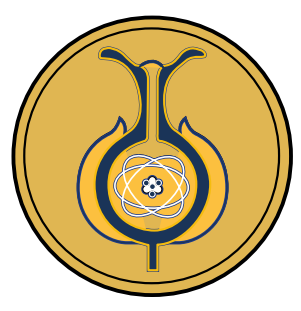

\title{
Spectral reconstruction of kilovoltage photon beams using generalized simulated annealing
}

\author{
Reconstrucción espectral de haces de fotones de kilovoltaje por medio de \\ recocido simulado generalizado \\ Reconstrução espectral de feixes de fótons de kilovoltagem através do \\ recozimento simulado generalizado
}

\section{Jorge Homero Wilches-Visbal ${ }^{1}$, Danny Giancarlo Apaza-Veliz ${ }^{2}$, Patrícia Nicolucci ${ }^{2}$}

\section{Received: Jul/15/2021 • Accepted: Set/1/2021 • Published: Jan/31/2022}

\begin{abstract}
D)
[Objective] To unfold the energy spectrum of two kilovoltage (KV) X-ray beams from transmission curves through a mathematical methodology based on Laplace transform and the generalized simulated annealing algorithm. [Methodology] Energy spectra of photon beams and transmission data were associated by means of a mathematical expression derived from the analytical solution of Laplace transform. Transmission data was calculated by relating the air kerma of the attenuated beams, passing through aluminium plates of different thickness, to that of the non-attenuated beam. Generalized simulated annealing function, developed in an early work, was employed to find the parameters of the expression and so determine the spectra. Validation of the methodology was done by the comparison of the half-value layers obtained from transmission curves and the spectra. [Results] The mean square percentage error between transmission data and fitting curve of each spectrum defined from the parameters found was lower than $1 \%$ indicating a good adjustment. The same error was observed when the first half-value layer (HVL) from the transmission curves and those of each reconstructed spectrum were compared. Calculation time of parameters was 5 sec for $80 \mathrm{kV}$ and 14 sec for $120 \mathrm{kV}$. In no case, non-realistic solution of energy spectra was obtained. These results were better than an early work where leastsquares were used. [Conclusion] The reconstruction methodology based on generalized simulated annealing employed in this manuscript can efficiently derive the spectra of two X-ray beams with comparable accuracy to previous work. A limitation is that validation was not done by comparing data with the equipment's spectra.
\end{abstract}

Keywords: photon spectra; generalized simulated annealing; inverse reconstruction; transmission curves

\section{Resumen (10)}

Determinar el espectro de energía de dos haces de rayos $\mathrm{X}$ de kilovoltaje $(\mathrm{kV})$, a partir de sus curvas de transmisión, mediante una metodología matemática basada en la transformada de Laplace y el algoritmo de

Jorge Homero Wilches-Visbal, \jwilches@unimagdalena.edu.co, (iD https://orcid.org/0000-0003-3649-5079

Danny Giancarlo Apaza-Veliz, \ dveliz@usp.br, (D) https://orcid.org/0000-0001-7645-2626

Patrícia Nicolucci, 『 nicol@usp.br, (D) https://orcid.org/0000-0001-6501-1489

1 Facultad de Ciencias de la Salud, Universidad del Magdalena, Santa Marta, Colombia.

2 Departamento de Física, Universidade de São Paulo, Ribeirão Preto, Brasil. 
recocido simulado generalizado. Los espectros de energía de los haces y los datos de transmisión se asociaron, por medio de una expresión matemática derivada de la solución analítica de la transformada de Laplace. Los datos de transmisión se calcularon relacionando el kerma de aire de los haces atenuados, al pasar por placas de aluminio de diferente espesor, con el de los no atenuados. La función de recocido simulado generalizada, desarrollada en un trabajo anterior, se empleó para descifrar los parámetros de la expresión y así obtener los espectros. La validación se realizó comparando las capas semirreductoras de las curvas de transmisión y las extraídas de los espectros. El error porcentual cuadrático medio entre los datos de transmisión y la curva de ajuste para cada espectro, definido a partir de los parámetros encontrados, fue inferior al $1 \%$, lo que indica un buen ajuste. Se observó el mismo error cuando se cotejó la primera capa semirreductora de las curvas de transmisión y las de cada espectro reconstruido. El tiempo de cálculo de los parámetros fue de $5 \mathrm{~s}$ para 80 kV y 14 s para 120 kV. En ningún caso se obtuvo una solución no realista de los espectros. Estos resultados fueron mejores que los de un trabajo anterior en el que se utilizaron mínimos cuadrados. La metodología de reconstrucción basada en recocido simulado generalizado, empleada en este manuscrito, pudo derivar de manera eficiente los espectros de dos haces de kilovoltaje con una precisión comparable a la de trabajos anteriores. Una limitación es que la validación no se realizó comparando con los espectros del equipo.

Palabras clave: Espectros de fotones; recocido simulado generalizado; reconstrucción inversa; curvas de transmisión

\section{Resumo}

Encontrar o espectro de energia de dois feixes de raios-X de quilovoltagem a partir das curvas de transmissão por meio de uma metodologia matemática baseada na transformada de Laplace e no algoritmo de recozimento simulado generalizado. Os espectros de energia e os dados de transmissão foram associados por meio de uma expressão matemática derivada da solução analítica da transformada de Laplace. Os dados de transmissão foram calculados relacionando o kerma no ar dos feixes atenuados, ao passar por placas de alumínio de diferentes espessuras, com o dos feixes não atenuados. A função de recozimento simulado generalizado, desenvolvida em um trabalho anterior, foi empregada para encontrar os parâmetros da expressão para assim determinar os espectros. A validação da metodologia foi feita pela comparação das camadas semirredutoras obtidas das curvas de transmissão e dos espectros. 0 erro percentual médio quadrático entre os dados de transmissão e a curva de ajuste, para cada espectro definido a partir dos parâmetros encontrados, foi menor do que 1\%, indicando um bom ajuste. 0 mesmo erro foi observado quando comparada a primeira camada semirredutora das curvas de transmissão e aquelas de cada espectro reconstruído. 0 tempo de cálculo dos parâmetros foi de 5 s para $80 \mathrm{kV}$ e 14 s para $120 \mathrm{kV}$. Em nenhum caso, solução não realista dos espectros foi obtida. Os resultados foram melhores do que um trabalho anterior onde mínimos quadrados foram usados. A metodologia de reconstrução fundamentada no recozimento simulado generalizado, empregada neste trabal ho, pôde derivar eficientemente os espectros de dois feixes de raios-X com precisão comparável a trabalhos anteriores. Uma limitação é que a validação não foi feita por comparação com os espectros do equipamento.

Palavras-chave: espectros de fótons; recozimento simulado generalizado; reconstrução inversa; curvas de transmissão. 


\section{Introduction}

$\mathrm{X}$-rays are widely used in industry, engineering, health sciences and other areas for applications such as material characterization, analysis of fatigue and fractures in materials, and medical diagnostic or therapeutic purposes (Bilge, 2004; Carrera et al., 2019; Durán-Nava et al., 2019; Epp, 2016).

The energy and intensity of the X-ray beam employed differs for each application. In medical diagnostic and therapy, superficial X-rays ranging from approximately 50 to $250 \mathrm{keV}$ are used to produce images of different parts of the body or to treat skin cancers (Hill et al., 2014; Tafti \& Maani, 2020).

The contrast of the radiographic image, as well as the delivered dose to the patient, depend critically on the X-ray energy spectrum. The spectrum can be also important to characterize the dosimetric properties of the beam (Chen et al., 2012), for quality control of mammography equipments and x-ray tubes (Abbene et al., 2012; Maeda et al., 2005; Querol et al., 2010), and optimization of image quality parameters (Malezan et al., 2015).

The X-ray production is commonly influenced by the tube's peak potential $(\mathrm{kVp})$, electronic current $(\mathrm{mA})$, anode material and filtration (Nakashima \& Duong, 2020; Sharma et al., 2015; Tafti \& Maani, 2020; Thunthy \& Manson-Hing, 1978). The energy spectrum of an X-rays beam is defined as the energy distribution of the produced photons (Nickoloff \& Berman, 1993; Tafti \& Maani, 2020).

Experimental, computational, or mathematical methods can be used to assess the energy spectrum of an X-ray beam. Experimental methods are based on the direct measurement of the spectrum by means of a Compton spectrometer. Monte Carlo method can be used to computationally simulate the produced X-rays. Mathematical methods usually derive the spectrum from experimental transmission curves of the $\mathrm{X}$-rays by a given material (Chen et al., 2012; Hill et al., 2014).

Some difficulties of experimental and computational approaches are related to the cost of the spectrometer, specific information about the geometry and materials of the $\mathrm{X}$-ray equipment for use in the Monte Carlo modelling (Baird, 1981; Hill et al., 2014) and expertise (Menin et al., 2016). Furthermore, softwares as SpekCalc only allow calculations for a fixed source-detector distance (Poludniowski et al., 2009).

In the present work, transmission curves are used to obtain the energy spectra from a clinical orthovoltage equipment. Inverse Laplace transform of the transmission data (Benjamin R. Archer \& Wagner, 1988 ) is employed along with the generalized simulated annealing (Wilches Visbal \& Da Costa, 2019).

\section{Methodology}

\section{Mathematical modelling}

In radiation physics it is possible to related the air collision kerma $K_{\mathrm{col}}$ to the energy distribution fluence of a photon beam $\Phi(E)$ as (Menin et al., 2016),

$$
\begin{aligned}
& K_{c o l}=\int_{0}^{E_{\max }} E \Phi(E)\left(\frac{\mu_{e n}}{\rho}\right) d E(1) \\
& \text { where }\left(\frac{\mu_{e n}}{\rho}\right) \text { is the mass absorption }
\end{aligned}
$$

coefficient for photons with nominal energy $E$, and $E_{\max }$ the maximum energy of the beam, determined by the voltage peak of the $\mathrm{X}$-ray tube. 
For a narrow beam, the attenuated energy distribution fluence obtained as an $\mathrm{X}$-ray beam traversed an absorber material of thickness $x$ is,

$$
\Phi_{x}(E)=\Phi_{0}(E) \exp \left(-\mu_{m} x\right)(2)
$$

where $\Phi_{0}(E)$ is the non-attenuated energy distribution fluence of the beam $(x=0)$ and $\mu_{\mathrm{m}}$ is the mass attenuation coefficient of the absorber, which is a function of $E$.

Substituting eq. (2) in (1), the $K_{\mathrm{col}}$ for an attenuated $\mathrm{X}$-ray beam is,

$K_{c o l, x}=\int_{0}^{E_{\max }} E \Phi_{0}(\mathrm{E}) \exp \left(-\mu_{m}(E) x\right)\left(\frac{\mu_{e n}}{\rho}\right) d E$,

meanwhile for a non-attenuated beam the $K_{\text {air }}$ is,

$$
K_{c o l, 0}=\int_{0}^{E_{\max }} E \Phi_{0}(E)\left(\frac{\mu_{e n}}{\rho}\right) d E
$$

From eq. (3) and (4) the relative transmission is obtained as,

$T(x)=\frac{\int_{0}^{E_{\max }} E \Phi_{0}(E) \exp \left(-\mu_{m}(E) x\right)\left(\frac{\mu_{e n}}{\rho}\right) d E}{\int_{0}^{E_{\max }} E \Phi_{0}\left(\frac{\mu_{e n}}{\rho}\right) d E}$

or also,

$$
T(x)=\frac{K_{c o l, x}}{K_{c o l, 0}},(6)
$$

where $K_{\mathrm{col}, 0}$ is obtained from an ionization chamber reading without absorber and $K_{\text {col, } \mathrm{x}}$ is the reading with an absorber of thickness $x$ between the X-ray source and the detector, considering the influence variables (e.g., temperature and pressure) and calibration coefficient of the detector (Smith, 2000).
Considering that (Pamplona \& Costa, 2010)

$$
F(E)=\frac{E \Phi_{0}(E)\left(\frac{\mu_{e n}}{\rho}(E)\right)}{K_{\text {col }, 0}},(7)
$$

and substituting eq. (7) in eq. (5)

$$
T(x)=\int_{0}^{E_{\max }} F(E) \exp \left(-\mu_{m} x\right) d E
$$

Changing the integration variable from $E$ to $\mu_{\mathrm{m}}$,

$$
F(E)\left(-\frac{d E}{d \mu_{m}}\right)=f\left(\mu_{m}\right),(9)
$$

eq. (8) becomes,

$$
T(x)=\int_{0}^{E_{\max }} f\left(\mu_{m}\right) \exp \left(-\mu_{m} x\right) d \mu_{m}
$$

assuming that $\mu_{\mathrm{m}}$ is a monotonic and decrescent function with the energy. As eq. (10) complies with the definition of Laplace transform (L) (B. Archer \& Wagner, 1982),

$$
T(x)=\mathcal{L}\left[f\left(\mu_{m}\right)\right] .(11)
$$

If the transmission curve is known, then $f\left(\mu_{\mathrm{m}}\right)$ is obtained by the inverse Laplace transform,

$$
f\left(\mu_{m}\right)=\mathcal{L}^{-1}[T(x)] .(12)
$$

So, the energy spectrum can be determined as (B. R. Archer et al., 1985; B. Archer \& Wagner, 1982)

$$
F(E)=-f\left(\mu_{m}\right) \frac{d \mu_{m}}{d E}
$$

Math conditions for obtaining the transmission and energy spectrum from eq. 
(10) and (13) are exposed in B. Archer \& Wagner, (1982).

In this work, the best model that for such requirements (B. R. Archer et al., 1985) was assumed, but including characteristic radiation (Benjamin R. Archer \& Wagner, 1988). Hence, the transmission over a material of thickness $x$ becomes,

$$
\begin{gathered}
T(x)=r\left[\frac{a b}{(x+a)(x+b)}\right]^{v} \exp \left(-\mu_{m, 0} x\right) \\
+(1-r) \sum_{i} C_{i} \exp \left(-\mu_{m, i} x\right),(12)
\end{gathered}
$$

where $a, b$ and $v$ are fitted parameters; $\mu_{\mathrm{m}, 0}$ is the mass attenuation coefficient at the nominal energy of the beam; $r$ is the fraction of the bremsstrahlung component; $C_{i}$ is the relative abundance of the $\mathrm{i}$-th characteristic $\mathrm{X}$-ray line and $\mu_{\mathrm{m}, \mathrm{i}}$ is the respective mass attenuation coefficient.

The energy spectrum of an X-ray beam is given by (Benjamin R. Archer \& Wagner, 1988),

$$
\begin{gathered}
F(E)=\frac{r \pi^{1 / 2}(a b)^{2}}{\Gamma(v)}\left(\frac{\mu_{m}-\mu_{m, 0}}{a-b}\right)^{v-1 / 2} \\
\exp \left(\frac{-(a+b)}{2}\left(\mu_{m}-\mu_{m, 0}\right)\right) \Gamma_{v-1 / 2} \\
\left(\frac{1}{2}(a-b)\left(\mu_{m}-\mu_{m, 0}\right)\right)\left(-\frac{d \mu_{m}}{d E}\right) \\
+(1-r) \sum_{i} C_{i} \delta\left(E-E_{\mathrm{i}}\right)(13)
\end{gathered}
$$

function, and $\delta\left(E-E_{\mathrm{i}}\right)$ is the Dirac delta function of the difference between the nominal energy $E$ and the energy of the i-th characteristic X-ray line.

The purpose is to find the $a, b$ and $r$ parameters in the eq. (5) by using an optimization function to determine the spectrum $F(E)$. Benjamin R. Archer \& Wagner, (1988) published values of $C_{\mathrm{i}}$ and $\mu_{\mathrm{m}, \mathrm{i}}$. For finding the $\left(-\frac{d \mu_{m}}{d E}\right)$ it is necessary to fit $\mu_{\mathrm{m}}$ to a fifth degree polynomial (B. R. Archer et al., 1985).

\section{Generalized simulated annealing function (GSA)}

To assess the values of $a, b$ and $r$ from eq. (5) it is necessary to use an optimization method for minimizing the residual norm of $T(x)$. Among the existing optimization algorithms, generalized simulated annealing (GSA) is one of most popular and efficient. GSA is a metaheuristic method for solving optimization problems where the global optimum is behind many local minima. GSA mimics the physical annealing, where a metal is heated up to a high temperature for later slowly cooling until reaching a crystalline structure free from imperfection (Wilches Visbal \& Da Costa, 2019).

In GSA, there are three important factors for convergence to the global optimum: i) visiting distribution $\left(g_{v}\right)$; ii) acceptance probability $\left(P_{\mathrm{a}}\right)$, and iii) cooling schedule $\left(T_{\mathrm{v}}\right)$. The first factor is related to the achievement of a new solution from the current one; the second factor is associate with an acceptance rule of a new solution, and the third one refers to the capacity of allowance of solutions far from the current one (Deng et al., 2004; Wilches Visbal \& Da Costa, 2019).

In a recently work, the GSA function inspired by the generalized simulated annealing algorithm was developed in MATLAB ${ }^{\circledR}$ (Wilches Visbal \& Da Costa, 2019). The basic form of the function is:

$$
\left[s, f_{v a l}, t\right]=\operatorname{GSA}\left(f, s_{o}, l, u, q_{v}, q_{a}, I_{\max }\right),(1
$$

where $s$ is the solution vector; $f_{\text {val }}$ is the value of the objective function (or 
functional) $f$ in the solution; $s_{\mathrm{o}}$ is the initial point; $l$ is the lower bound; $u$ is the upper bound; $q_{\mathrm{u}}$ is the visiting parameter, $q_{\mathrm{a}}$ is the acceptance parameter, and $I_{\text {max }}$ is the maximum number of iterations.

Figure 1 shows the basic flowchart of the GSA algorithm contained in the GSA function.

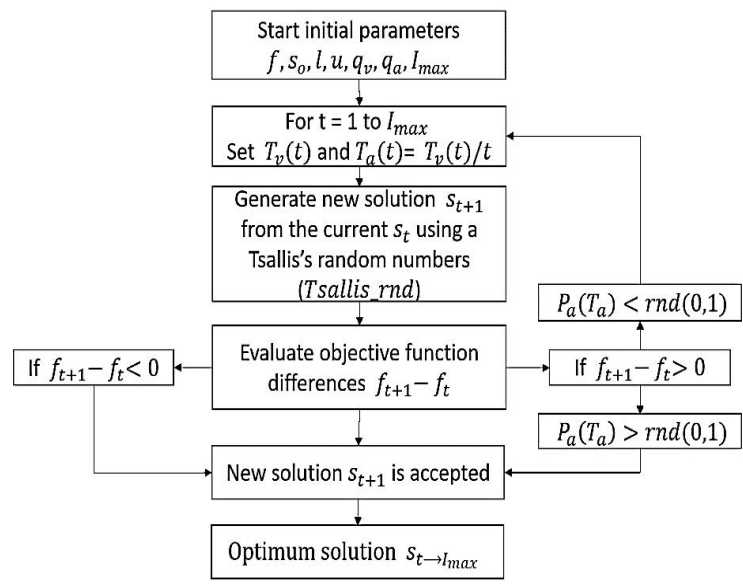

Figure 1. Flowchart of the GSA algorithm used in the reconstruction process. Note: derived from research.

The efficiency of GSA function was tested for optimization problems of varying complexity and has also been used for the assessment of electron beam spectra (Visbal \& Costa, 2019).

\section{Reconstruction methodology}

The steps for deriving the spectra of $\mathrm{X}$-rays beams are the following (Gonçalves et al., 2020):

1. Determination of experimental transmission data: X-ray beams from a Siemens Stabilipan-II from Hospital of Clinics at Ribeirão Preto, Brazil, were used to irradiate aluminum plates (purity better than $99 \%$ ) of different thicknesses $(\mathrm{cm})$. X-ray beams were ad- justed with the inner collimator of the equipment for a field size of $10 \times 10$ $\mathrm{cm}^{2}$. Thickness of each plate was converted to specific thickness $\left(\mathrm{g} / \mathrm{cm}^{2}\right)$ considering the density of aluminum as 2.7 $\mathrm{g} / \mathrm{cm}^{3}$. Beams produced at $80 \mathrm{kVp}(x=$ $0.0 \mathrm{~cm}$ up to $0.5 \mathrm{~cm}$ ) and $120 \mathrm{kVp}$ tube voltages $(x=0.0 \mathrm{~cm}$ up to $0.7 \mathrm{~cm})$ were used. The aluminum plates were placed at the output window of the equipment.

A Radcal 2086 ionization chamber was used to obtain the air kerma for non-attenuated beams (without plates) and for attenuated (or transmitted) beams (with plates). The distance from the radiation source to the center of ionization chamber was $40 \mathrm{~cm}$. The transmission values were calculated by means of eq. (12).

2. Calculation of parameters of the transmission $T(x)$ : Objective function $\gamma(T)$, given by

$$
\begin{gathered}
\gamma(T)=\| T(x)-r\left[\frac{a b}{(x+a)(x+b)}\right]^{\vartheta} \exp \left(-\mu_{m, 0} x_{j}\right) \\
+(1-r) \sum_{i} C_{i} \exp \left(-\mu_{m, i} x_{j}\right) \|_{2}^{2}(15)
\end{gathered}
$$

was minimized employing the GSA function (i.e., $\gamma(T)=f$ in Fig. 1), with $q_{\mathrm{v}}=2.7, q_{\mathrm{a}}=-5$ and $I_{\max }=200$. The bounds imposed were $0<$ $a<10 ; 0<b<1,0<v<1$ and $0<r<1$. Initial point was a vector of random numbers. $I_{\max }=$ 100 for $80 \mathrm{kVp}$ and 300 for the $120 \mathrm{kVp}$ beam.

The stopping condition for the reconstruction algorithm was that the mean square percentage error (MSPE) between experimental transmission data and those from the fitted transmission curve were lower than $1 \%$. The same limit was set to the relative error between the HVL of the transmission curve and the derived one from the spectrum. 
3. Calculation of the $F(E)$ : Once the parameters of eq. (15) have been found, they are replaced in eq. (7) for obtaining the spectrum of each X-ray beam. $\left(-\frac{d \mu_{m}}{d E}\right), \Gamma(v)$ and $\delta\left(E-E_{\mathrm{i}}\right)$ were computed applying the functions fit, gam$m a$ and KronD of MATLAB ${ }^{\circledR}$. Lastly, the spectrum was obtained by normalizing $F(E)$ to its maximum value.

Validation of the reconstruction methodology was obtained by the comparison between the HVLs from the transmission curves $\left(H V L_{\mathrm{T}(\mathrm{x})}\right)$ and from the spectra $\left(H V L_{\mathrm{F}(\mathrm{E})}\right)$, since real (experimental) spectra were not available. $H V L_{\mathrm{F}(\mathrm{E})}$ is calculated as,

$H V L_{F(E)}=\frac{x_{1} \ln \left(\frac{2 K_{a r, 2}}{K_{a r, 0}}\right)-x_{2} \ln \left(\frac{2 K_{a r, 1}}{K_{a r, 0}}\right)}{\ln \left(\frac{K_{a r, 2}}{K_{a r, 1}}\right)}$

where $K_{\mathrm{ar}, 0}, K_{\mathrm{ar}, 1}$ and $K_{\mathrm{ar}, 2}$ are the air kerma values measured without absorber material $\left(x_{0}=0\right)$ and with absorber with a thickness immediately lower $\left(x_{1}\right)$ and greater $\left(x_{2}\right)$ than the HVL value of the transmission curve, respectively (Gonçalves et al., 2020).

Air kerma of both X-rays beams was computed by utilizing the following equation (Gonçalves et al., 2020),

$K_{\text {air }}\left(x_{j}\right)=\sum_{i}^{n} F(E)_{i} M(0) \exp \left(-\mu_{m, 0} x_{j}\right) \Delta E_{i}$,

where $\mathrm{i}=[1,2, \ldots n]$ is the $\mathrm{i}$-th energy beam $E_{\mathrm{i}}$ that makes up the X-ray spectrum, $n$ is the index of the maximum energy beam of photons that makes up the X-ray spectrum; $\mathrm{j}=[0,1,2, . ., 5]$ is the $\mathrm{j}$-th value of the thickness of the absorbing material and $\Delta E_{\mathrm{i}}$ the chosen energy interval.

Calculations involved in the reconstruction process were performed with MATLAB ${ }^{\circledR} 2017 \mathrm{a}$ in a personal computer running with Microsoft Windows 10 Pro 64-bit (Core: i7, CPU: $1.8 \mathrm{GHz}, \mathrm{RAM}: 12 \mathrm{~Gb}$ ).

\section{Analysis and Results}

Figure 2 shows the normalized transmission for the $80 \mathrm{kVp}$ (a) and $120 \mathrm{kVp}$ (b)

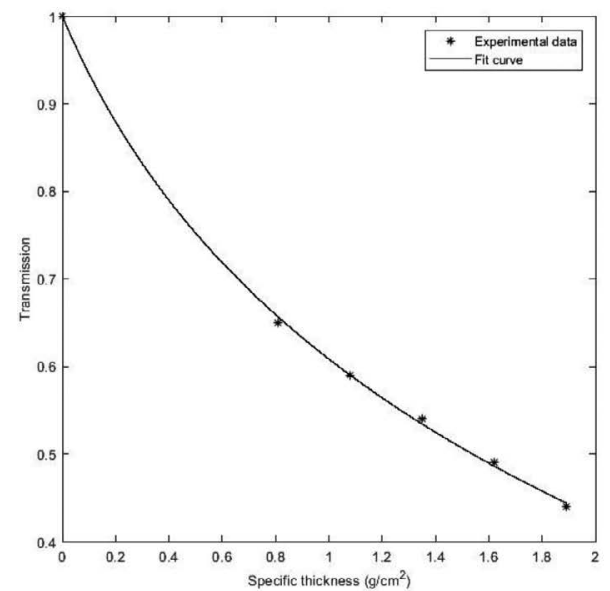

(a)

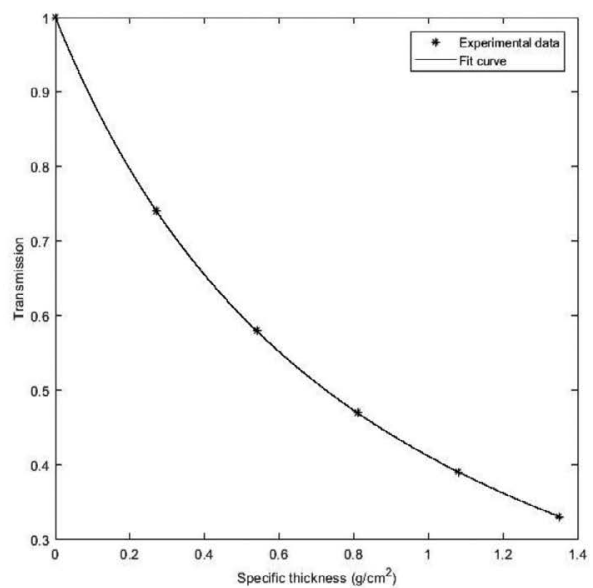

(b)

Figure 2. Transmission of $80 \mathrm{kVp}(\mathrm{a})$ and $120 \mathrm{kVp}$ (b) X-ray beams. Curves were found from minimizing process associated to eq. (15).

Note: derived from research. 
X-ray beams. The curves are exponentially decreasing with the thickness of aluminum plates, as expected.

In Table 1 the values of fitted parameters by means of the minimization process of the functional $\gamma(T)$ are shown.

Table 1

Non-linear fit parameters found from the minimization of the functional $\gamma(T)$ for the $80 \mathrm{kVp}$ and $120 \mathrm{kVp}$ X-ray beams.

\begin{tabular}{lcccc}
\hline \multicolumn{1}{c}{ Beam energy } & $\boldsymbol{a}$ & $\boldsymbol{b}$ & $\boldsymbol{v}$ & $\boldsymbol{r}$ \\
\hline $80 \mathrm{kVp}$ & 3.394 & 0.660 & 0.711 & 0.855 \\
$120 \mathrm{kVp}$ & 7.893 & 0.594 & 0.506 & 0.565 \\
\hline
\end{tabular}

Note: derived from research.

The residual norms of eq. (15) were $4.3 \times 10^{-5}$ and $1.0 \times 10^{-4}$ for the $80 \mathrm{kVp}$ and the $120 \mathrm{kVp}$ beams respectively, whilst the parameters calculation times were $5 \mathrm{sec}$ and $14 \mathrm{sec}$ approximately. The MSPEs were $0.79 \%$ and $0.82 \%$ for the $80 \mathrm{kVp}$ and the $120 \mathrm{kVp}$ beams, respectively. Determination coefficient was greater than 0.99 . The good adjustment between transmission data and curves indicates that the values of

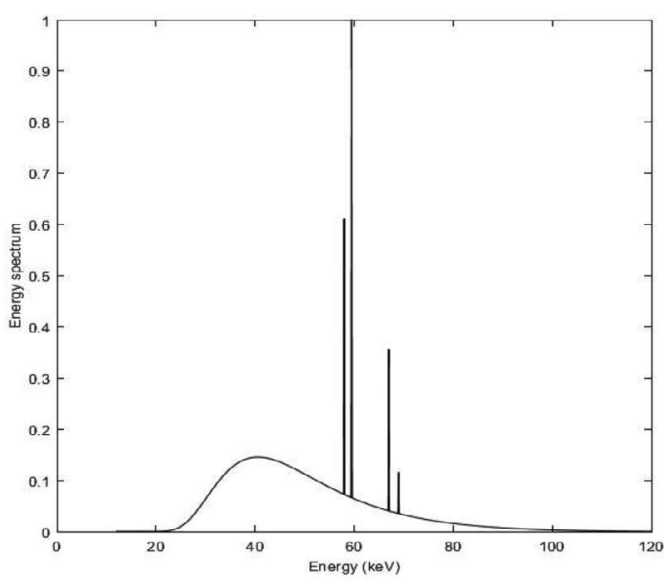

(a) parameters are adequate for assessing the spectra from eq. (13).

Figure 3 shows the normalized energy spectrum of the $80 \mathrm{kVp}$ (a) and $120 \mathrm{kVp}$ (b) $\mathrm{X}$-ray beams obtained by substituting the parameters of Table 1 in eq. (13).

The spectra are right-skewed normal distributions where the peak is the most probable bremsstrahlung energy. The bremsstrahlung component was close to $90 \%$ of the total fluence for the $80 \mathrm{kVp}$ beam and approximately $57 \%$ for the $120 \mathrm{kVp}$ beam. It is also observed the presence of characteristic X-ray lines in 58, 59.5, 67 and 69 $\mathrm{kV}$, corresponding to the Tungsten-anode $\mathrm{K}$-edge energies. The most probable energy was located at $29.8 \mathrm{keV}$ for the $80 \mathrm{kVp}$ beam and at $40.4 \mathrm{keV}$ for the $120 \mathrm{kVp}$ beam.

For the validation of the reconstruction process, the first HVLs given by the transmission curve and the energy spectrum, were compared. $H V L_{\mathrm{T}(\mathrm{x})}$ was computed by inverse interpolation to $T=0.5$ and $H V L_{\mathrm{F(E)}}$ was calculated using the eq. (10). For the 80 $\mathrm{kVp}$ beam $K_{\mathrm{ar}, 0}=3.23 \times 10^{3} \mathrm{~Gy}, K_{\mathrm{ar}, 1}=1.58$ x $10^{3}$ Gy and $K_{\text {ar, }}=1.82 \times 10^{3}$ Gy when $x_{1}$

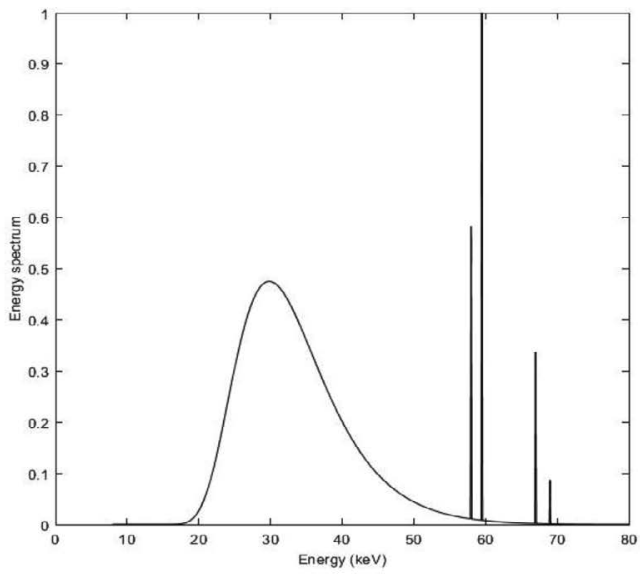

(b)

Figure 3. Normalized energy spectrum of $80 \mathrm{kVp}$ (a) and $120 \mathrm{kVp}$ (b) X-ray beams. Spectra were computed by using the eq. (13) from parameters found. Note: derived from research. 
$=0.58 \mathrm{~cm}$ and $x_{2}=0.74 \mathrm{~cm}$ was employed. Meanwhile, for the $120 \mathrm{kVp}$ beam $K_{\mathrm{ar}, 0}=$ $2.90 \times 10^{3}$ a Gy, $K_{\mathrm{ar}, 1}=1.34 \times 10^{3} \mathrm{~Gy}$ and $K_{\mathrm{ar}, 2}=1.57 \times 10^{3}$ Gy when $x_{1}=1.35 \mathrm{~cm}$ and $x_{2}=1.63 \mathrm{~cm}$ was used.

In the Table 2 are shown the values of $H V L_{\mathrm{T}(\mathrm{x})}$ and $H V L_{\mathrm{F}(\mathrm{E})}$ for the $80 \mathrm{kVp}$ and 120 $\mathrm{kVp}$ X-ray beams.

Table 2

Values of HVL from the transmission curves $(T(x))$ and the reconstructed $X$-ray spectra $(F(E))$ of $80 \mathrm{kVp}$ and $120 \mathrm{kVp}$.

\begin{tabular}{|c|c|c|c|}
\hline \multicolumn{2}{|c|}{$\mathrm{HVL}_{\mathrm{T}(\mathrm{x})}\left(\mathrm{g} / \mathrm{cm}^{2}\right)$} & \multicolumn{2}{|c|}{ HVL $_{\mathrm{F(E)}}\left(\mathrm{g} / \mathrm{cm}^{2}\right)$} \\
\hline $80 \mathrm{kVp}$ & $120 \mathrm{kVp}$ & $80 \mathrm{kVp}$ & $120 \mathrm{kVp}$ \\
\hline 0.725 & 1.538 & 0.720 & 1.537 \\
\hline
\end{tabular}

Note: derived from research.

The percent relative errors between HVL values are lower than $1 \%$ for both the $80 \mathrm{kVp}$ and $120 \mathrm{kVp}$ beam. This indicates an accuracy improvement regarding previously reported results in literature, where the percent relative error was $2.65 \%$ for the 80 $\mathrm{kVp}$ beam. Furthermore, unlike Gonçalves et al., (2020), it was possible to reconstruct a realistic spectrum (without negative values) of the $120 \mathrm{kVp}$ beam.

Moreover, it was not necessary to impose additional conditions for avoiding the determination of non-realistic spectra related to values of $v$ lower than 0.6 , as used by B. R. Archer \& Wagner, (1988). On the other hand, unlike Menin et al., (2016), in this work no regularization parameter for obtaining smoothing spectra was employed. A limitation of this work was that the reconstructed spectra could not compared with actual ones as done elsewhere (Malezan et al., 2015; Menin et al., 2016).

Hence, the reconstruction methodology employed in this work can be considered a good option for deriving spectra with speediness and accuracy. It is also useful to validate the obtained spectrum when it is not possible to compare with a real, theoretical, or simulated one.

\section{Conclusion}

The mathematical methodology proposed in this article was capable of efficiently and quickly reconstruct the energy spectra of two orthovoltage X-ray beams. Such methodology was based on the GSA function developed in an early manuscript of one of the authors. Calculation time of spectra reconstruction did not exceed $15 \mathrm{sec}$, although it may vary due to the stochastic nature of the generalized simulated annealing.

In general terms, this methodology exhibited better results than an early work that applied the multistart-lsqnonlin function of MATLAB. Moreover, it did not need to employ any regularization method as seen in other works. On the other hand, unlike SpekCalc, this methodology can be applied to obtain spectra to source-surface distances lower than $100 \mathrm{~cm}$, commonly found in radiodiagnostic.

A future work should considerer the comparison with real spectra obtained from Monte Carlo simulation or Compton spectrometry. It also would be interesting to explore this methodology to reconstruct megavoltage photon spectra due their relevance in radiation therapy.

\section{Acknowledgment}

To BSc. Ana Carolina Goncalves for sharing the data of transmission.

\section{Conflict de interest}

No conflict of interest among authors. 


\section{Author contribution statement}

The total contribution percentage for the conceptualization, preparation, and correction of this paper was as follows: J.H.W.V 50\%, D.G.A.V. 30\%, P.N. 20\%.

\section{Data availability statement}

The data supporting the results of this study will be made available by the corresponding author, J.H.W.V, upon reasonable request.

\section{References}

Abbene, L., Gerardi, G., Principato, F., Del Sordo, S., \& Raso, G. (2012). Direct Measurement of Mammographic X-Ray Spectra with a Digital CdTe Detection System. Sensors, 12(6), 83908404. https://doi.org/10.3390/s120608390

Archer, B. R., \& Wagner, L. K. (1988). A modified X-ray spectra reconstruction technique. Physics in Medicine and Biology, 33(12), 1399-1406. https://doi. org/10.1088/0031-9155/33/12/005

Archer, B. R., Wagner, L. K., Johnston, D. A., Almond, P. R., \& Bushong, S. C. (1985). Analysis of errors in spectral reconstruction with a Laplace transform pair model. Physics in Medicine and Biology, 30(5), 411-418. https://doi.org/10.1088/0031-9155/30/5/004

Archer, B., \& Wagner, L. (1982). A Laplace transform pair model for spectral reconstruction. Medical Physics, 9(6), 844-847. https://doi. org/10.1118/1.595193

Archer, Benjamin R., \& Wagner, L. K. (1988). Determination of diagnostic $\mathrm{X}$-ray spectra with characteristic radiation using attenuation analysis. Medical Physics, 15(4), 637-641. https://doi.org/10.1118/1.596220

Baird, L. C. (1981). X-ray spectra vs attenuation data: A theoretical analysis. Medical Physics, 8(3), 319-323. https://doi.org/10.1118/1.594834

Bilge, H. (2004). Beam characteristics of kilovoltage radiotherapy unit. Journal of B.U.ON., 9(3), 303-306. https://pubmed.ncbi.nlm.nih. gov/17415831/
Carrera, M., Lopez-Crespo, P., Tai, Y. H., Yates, J. R., Moreno, B., Buslaps, T., \& Withers, P. J. (2019). Estimation of the plastic zone in fatigue through the thickness based on synchrotron diffraction data. Procedia Structural Integrity, 17, 872-877. https://doi. org/10.1016/j.prostr.2019.08.116

Chen, S. C., Jong, W. L., \& Hharun, A. Z. (2012). Evaluation of X-ray beam quality based on measurements and estimations using SpekCalc and Ipem78 models. Malaysian Journal of Medical Sciences, 19(3), 22-28. https:// pubmed.ncbi.nlm.nih.gov/23610546/

Deng, J., Chen, H., Chang, C., \& Yang, Z. (2004). A superior random number generator for visiting distribution in GSA. International Journal of Computer Mathematics, 81(1), 103120. https://doi.org/10.1080/0020716031000 1620768

Durán-Nava, O. E., Torres-García, E., Oros-Pantoja, R., \& Hernández-Oviedo, J. O. (2019). Monte Carlo simulation and experimental evaluation of dose distributions produced by a $6 \mathrm{MV}$ medical linear accelerator. Journal of Physics: Conference Series, 1221(1), 012079. https:// doi.org/10.1088/1742-6596/1221/1/012079

Epp, J. (2016). X-ray diffraction (XRD) techniques for materials characterization. Materials Characterization Using Nondestructive Evaluation (NDE) Methods. Elsevier. https://doi. org/10.1016/B978-0-08-100040-3.00004-3

Gonçalves, A. C., Wilches Visbal, J. H., \& Martins Da Costa, A. (2020). Determinación del espectro de energía de un haz de rayos $\mathrm{X}$ terapéutico de kilovoltaje a partir de su curva de atenuación. Revista de la Academia Colombiana de Ciencias Exactas, Físicas y Naturales, 44(170), 142-152. https://doi.org/10.18257/ raccefyn. 965

Hill, R., Healy, B., Holloway, L., Kuncic, Z., Thwaites, D., \& Baldock, C. (2014). Advances in kilovoltage x-ray beam dosimetry. Physics in Medicine and Biology, 59(6), 183-231. https:// doi.org/10.1088/0031-9155/59/6/R183

Maeda, K., Matsumoto, M., \& Taniguchi, A. (2005). Compton-scattering measurement of diagnostic x-ray spectrum using high-resolution Schottky CdTe detector. Medical Physics, 32(6Part1), 1542-1547. https://doi. org/10.1118/1.1921647 
Malezan, A., Tomal, A., Antoniassi, M., Watanabe, P. C. A., Albino, L. D., \& Poletti, M. E. (2015). Spectral reconstruction of dental X-ray tubes using laplace inverse transform of the attenuation curve. Radiation Physics and Chemistry, 116, 278-281. https://doi.org/10.1016/j. radphyschem.2015.05.008

Menin, O. H., Martinez, A. S., \& Costa, A. M. (2016). Reconstruction of bremsstrahlung spectra from attenuation data using generalized simulated annealing. Applied Radiation and Isotopes, 111, 80-85. https://doi.org/10.1016/j. apradiso.2016.02.014

Nakashima, J., \& Duong, H. (2020). Radiology, Image Production and Evaluation. StatPearls. https://www.ncbi.nlm.nih.gov/books/ NBK553145/

Nickoloff, E. L., \& Berman, H. L. (1993). Factors affecting $\mathrm{x}$-ray spectra. RadioGraphics, 13(6), 1337-1348. https://doi.org/10.1148/ radiographics.13.6.8290728

Pamplona, G. S. P., \& Costa, A. M. (2010). Determinação do espectro de raios $\mathrm{X}$ a partir da curva de transmissão para um equipamento de radiografia dentária. Revista Brasileira de Física Médica, 4(2), 23-25. https://doi. org/10.29384/rbfm.2010.v4.n2.p23-25

Poludniowski, G., Landry, G., DeBlois, F., Evans, P. M., \& Verhaegen, F. (2009). SpekCalc: a program to calculate photon spectra from tungsten anode $\mathrm{x}$-ray tubes. Physics in Medicine and Biology, 54(19), 433-438. https://doi. org/10.1088/0031-9155/54/19/N01

Querol, A., Gallardo, S., Ródenas, J., \& Verdú, G. (2010). Application of Tikhonov and MTSVD methods to unfold experimental X-ray spectra in the radiodiagnostic energy range. 2010 Annual International Conference of the IEEE Engineering in Medicine and Biology, 536-539. https://doi.org/10.1109/ IEMBS.2010.5626024
Sharma, R., Sharma, S., Pawar, S., Chaubey, A., Kantharia, S., \& Babu, D. A. R. (2015). Radiation dose to patients from X-ray radiographic examinations using computed radiography imaging system. Journal of Medical Physics, 40(1), 29. https://doi. org/10.4103/0971-6203.152244

Smith, F. A. (2000). A Primer in Applied Radiation Physics. En A Primer in Applied Radiation Physics (1th editio). WORLD SCIENTIFIC. https://doi.org/10.1142/3979

Tafti, D., \& Maani, C. V. (2020). Radiation X-ray Production. StatPearls. https://pubmed.ncbi. nlm.nih.gov/30725731/

Thunthy, K. H., \& Manson-Hing, L. R. (1978). Effect of $\mathrm{mAs}$ and $\mathrm{kVp}$ on resolution and on image contrast. Oral Surgery, Oral Medicine, Oral Pathology, 46(3), 454-461. https://doi. org/10.1016/0030-4220(78)90414-0

Visbal, J. H. W., \& Costa, A. M. (2019). Inverse reconstruction of energy spectra of clinical electron beams using the generalized simulated annealing method. Radiation Physics and Chemistry, 162, 31-38. https://doi. org/10.1016/j.radphyschem.2019.04.022

Wilches Visbal, J. H., \& Da Costa, A. M. (2019). Algoritmo de recocido simulado generalizado para Matlab. Ingeniería y Ciencia, 15(30), 117-140. https://doi.org/10.17230/ ingciencia.15.30.6

\section{(9) $(1 \Theta \Theta$}

Spectral reconstruction of kilovoltage photon beams using generalized simulated annealing (Jorge Homero Wilches-Visbal • Danny Giancarlo Apaza-Veliz • Patrícia Nicolucci) Uniciencia is protected by Attribution-NonCommercial-NoDerivs 3.0 Unported (CC BY-NC-ND 3.0) 